Subscriber access provided by Caltech Library

\title{
Communication
}

\section{Pb-activated Amine-assisted Photocatalytic Hydrogen Evolution Reaction on Organic-Inorganic Perovskites}

\author{
Lu Wang, Hai Xiao, Tao Cheng, Youyong Li, and William A. Goddard
}

J. Am. Chem. Soc., Just Accepted Manuscript • DOI: 10.1021/jacs.7b12028 • Publication Date (Web): 19 Jan 2018

Downloaded from http://pubs.acs.org on January 19, 2018

\section{Just Accepted}

"Just Accepted" manuscripts have been peer-reviewed and accepted for publication. They are posted online prior to technical editing, formatting for publication and author proofing. The American Chemical Society provides "Just Accepted" as a free service to the research community to expedite the dissemination of scientific material as soon as possible after acceptance. "Just Accepted" manuscripts appear in full in PDF format accompanied by an HTML abstract. "Just Accepted" manuscripts have been fully peer reviewed, but should not be considered the official version of record. They are accessible to all readers and citable by the Digital Object Identifier (DOI®). "Just Accepted" is an optional service offered to authors. Therefore, the "Just Accepted" Web site may not include all articles that will be published in the journal. After a manuscript is technically edited and formatted, it will be removed from the "Just Accepted" Web site and published as an ASAP article. Note that technical editing may introduce minor changes to the manuscript text and/or graphics which could affect content, and all legal disclaimers and ethical guidelines that apply to the journal pertain. ACS cannot be held responsible for errors or consequences arising from the use of information contained in these "Just Accepted" manuscripts. 


\title{
Pb-activated Amine-assisted Photocatalytic Hydrogen Evolution Re- action on Organic-Inorganic Perovskites
}

\author{
Lu Wang ${ }^{*}, \dagger,+$, Hai Xiao ${ }^{\ddagger}$, Tao Cheng ${ }^{\ddagger}$, Youyong $\mathrm{Li}^{*}{ }^{*}$, , and William A. Goddard III ${ }^{*}$, \\ ${ }^{\dagger}$ Institute of Functional Nano \& Soft Materials (FUNSOM), Jiangsu Key Laboratory for Carbon-Based Functional Materials \\ \& Devices, Soochow University, Suzhou, Jiangsu 215123, China \\ *Materials and Process Simulation Center (MSC) and Joint Center for Artificial Photosynthesis (JCAP), California Institute \\ of Technology, Pasadena, California 91125, United States
}

Supporting Information

\begin{abstract}
We report here the reaction mechanism for explicit aqueous solvent quantum mechanics (QM) studies determining the energetics and reaction barriers for the photocatalytic hydrogen evolution reaction (HER) on $\mathrm{CH}_{3} \mathrm{NH}_{3} \mathrm{PbI}_{3}$ surface. We find that both the lead $(\mathrm{Pb})$ atoms and the surface organic molecules play essential roles, leading to a two-step $\mathrm{Pb}$-activated amineassisted (PbAAA) reaction mechanism involving an intermediate lead hydride state. Both $\mathrm{H}$ of $\mathrm{H}_{2}$ product are extracted from surface organic molecules, while two protons from the solution migrate along water chains via the Grotthuss mechanism to replace the $\mathrm{H}$ in organic molecule. We obtain a reaction barrier of $1.08 \mathrm{eV}$ for photochemical generation of $\mathrm{H}_{2}$ on $\mathrm{CH}_{3} \mathrm{NH}_{3} \mathrm{PbI}_{3}$ compared to $2.61 \mathrm{eV}$ for the dark reaction. We expect this HER mechanism can also apply to the other organic perovskites but the energy barriers and reaction rates may depend on the basicity of electrolyte and intrinsic structures of perovskites.
\end{abstract}

Organic-inorganic hybrid perovskites are being widely applied to solar energy conversion with remarkably strong photovoltaic action and superior solar cell performance. ${ }^{1,2}$ The power conversion efficiencies have jumped from $3 \%$ to over $20 \%$ in just five years. Besides the high solar cell performance, the hybrid perovskites are promising candidates as light-emitting diodes, ${ }^{3-5}$ lasers, ${ }^{6,7}$ and photodetectors. ${ }^{8}$ The high-performance for photovoltaic properties of organic-inorganic hybrid perovskites arises from the low exciton binding energy ${ }^{9,10}$ and long carrier lifetime, ${ }^{11}$ leading to efficient electron-hole separation and carrier diffusion. These unique properties make the organic-inorganic perovskites promising photocatalytic semiconductors.

Recently, methylammonium lead iodide $\left(\mathrm{MAPbI}_{3}\right)$ was confirmed as a photocatalyst for $\mathrm{H}_{2}$ generation in aqueous $\mathrm{HI}$ solution. ${ }^{12}$ The $\mathrm{MAPbI}_{3}$ powder efficiently splits $\mathrm{HI}$ into $\mathrm{H}_{2}$ and $\mathrm{I}_{3}$ under visible light irradiation. In addition, studies on inorganic perovskites suggest them as photocatalysts for carbon dioxide reduction. ${ }^{13,14}$ However, there is no reaction mechanism to understand why the perovskites are efficient photocatalysts. Thus, it is important to understand the photocatalytic mechanisms in order to develop improved perovskites materials.

Photocatalytic hydrogen evolution reaction (HER) is an efficient method to convert solar energy to clean energy in the form of $\mathrm{H}_{2}$. Traditionally, $\mathrm{TiO}_{2}$ photocatalysts loaded with small amounts of Pt or Rh nanoparticles are utilized as the co-catalysts to generate $\mathrm{H}_{2}$ by splitting water under the UV light. ${ }^{15,16}$ In order to achieve a high conversion efficiency for generating $\mathrm{H}_{2}$ utilizing visible light, many photocatalytic semiconductors have been developed with suitable band gaps and good separation/migration of photoexcited holes and electrons. ${ }^{17,18}$ Here the organic-inorganic perovskites are particularly efficient because of their unique optoelectronic properties. In this communication, we use Quantum Mechanics (QM) in explicit solvent to derive the reaction mechanism for the photocatalytic HER reaction by the organic-inorganic $\mathbf{M A P b I}_{3}$ perovskite. We find that, in addition to serving as a photo-absorber for visible light, the $\mathbf{M A P b I}_{3}$ perovskite serves as a catalyst reductant in the HER reaction with both the lead atoms and the surface organic molecules playing a critical role.

The computational method are described in Supporting Information. We constructed a $2 \times 2$ supercell of the (010) surface of orthorhombic $\mathrm{MAPbI}_{3}$ perovskite in explicit aqueous acidic solution $(\mathrm{pH}=-0.48)$ with 3 Molar $\mathrm{HI}$ and two potassium atoms added to describe the photoexcited state (the extra two electrons delocalized over the lead atoms). The details of our structural model and the band structures are described and plotted in Fig. S1 of Supporting Information. One can consider four possible reaction pathways for $\mathrm{H}_{2}$ generation, with the two $\mathrm{H}$ atoms forming $\mathrm{H}_{2}$ derived from $\mathrm{H}_{2} \mathrm{O}, \mathrm{H}_{3} \mathrm{O}^{+}$or $\mathrm{CH}_{3} \mathrm{NH}_{3}{ }^{+}$molecules. These four reaction pathways are:

$$
\begin{aligned}
& \mathrm{H}^{*}\left(\mathrm{H}_{2} \mathrm{O}\right)+\mathrm{H}^{*}\left(\mathrm{H}^{+}\right)=\mathrm{H}_{2} \\
& \mathrm{H}^{*}\left(\mathrm{H}_{2} \mathrm{O}\right)+\mathrm{H}^{*}\left(\mathrm{CH}_{3} \mathrm{NH}_{3}{ }^{+}\right)=\mathrm{H}_{2} \\
& \mathrm{H}^{*}\left(\mathrm{H}^{+}\right)+\mathrm{H}^{*}\left(\mathrm{CH}_{3} \mathrm{NH}_{3}^{+}\right)=\mathrm{H}_{2} \\
& \mathrm{H}^{*}\left(\mathrm{CH}_{3} \mathrm{NH}_{3}^{+}\right)+\mathrm{H}^{*}\left(\mathrm{CH}_{3} \mathrm{NH}_{3}{ }^{+}\right)=\mathrm{H}_{2}
\end{aligned}
$$

First (case a in Fig. 1), we consider the case in which the only role of the $\mathrm{MAPbI}_{3}$ is to absorb visible light with no other involvement in the reaction. In this case, the $\mathrm{H}$ atoms of the $\mathrm{H}_{2}$ derive from $\mathrm{H}_{3} \mathrm{O}^{+}$and $\mathrm{H}_{2} \mathrm{O}$ in the solution. Here we examined the energetics for one $\mathrm{H}$ from $\mathrm{H}_{3} \mathrm{O}^{+}$to form $\mathrm{H}_{2}$ by combining with a nearby $\mathrm{H}$ in $\mathrm{H}_{2} \mathrm{O}$. The initial distance between these two $\mathrm{H}$ atoms is $3.17 \AA$ and the reaction path involves the $\mathrm{H}^{+}$in $\mathrm{H}_{3} \mathrm{O}^{+}$moving to the $\mathrm{H}$ in $\mathrm{H}_{2} \mathrm{O}$, with the $\mathrm{H}-\mathrm{H}$ distance decreasing to $1.71 \AA$ in the TS. We calculate an activation barrier of $2.28 \mathrm{eV}$, which is close 
to the standard Gibbs free energy of water formation with 2.46 $\mathrm{eV}$.
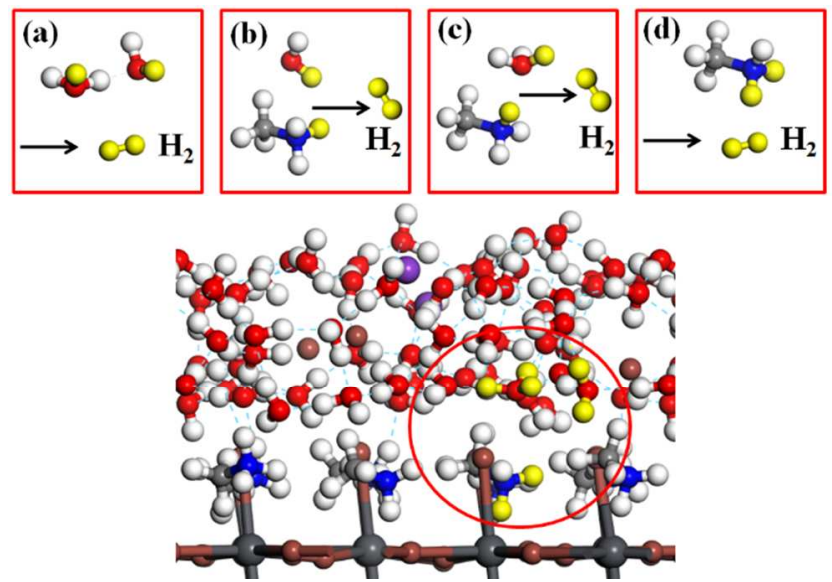

Fig. 1. Four possible reaction pathways for photocatalytic $\mathrm{H}_{2}$ generation on the $\mathrm{MAPbI}_{3}$ surface. The upper figure illustrates which $\mathrm{H}$ precursors form the $\mathrm{H}_{2}$ product, while the lower figure shows the structural model and origins of reactants. The two purple balls are the doped potassium atoms.

Second (case b in Fig. 1), we consider that the $\mathrm{MAPbI}_{3}$ could serve as a reactant in addition to absorbing the light. Here we start with one $\mathrm{H}$ from an upward $-\mathrm{NH}_{3}$ in $\mathrm{MA}^{+}$, and the other $\mathrm{H}$ is from a neighboring $\mathrm{H}_{2} \mathrm{O}$ at the interface. The initial distance between these two $\mathrm{H}$ is $2.94 \AA$, which decreases to $2.30 \AA$ in the TS as the $\mathrm{H}$ in $-\mathrm{NH}_{3}$ moves toward the $\mathrm{H}$ in the $\mathrm{H}_{2} \mathrm{O}$. The reaction barrier for this process is $1.94 \mathrm{eV}$, which is $0.34 \mathrm{eV}$ lower than the HER reaction between $\mathrm{H}_{2} \mathrm{O}$ and $\mathrm{H}_{3} \mathrm{O}^{+}$, but still quite high.

Third (case $\mathrm{c}$ in Fig. 1), we consider that the HER reaction occurs between one $\mathrm{H}$ from $-\mathrm{NH}_{3}$ in $\mathrm{MA}^{+}$and one $\mathrm{H}$ from $\mathrm{H}_{3} \mathrm{O}^{+}$. We choose a downward $\mathrm{MA}^{+}$interacting with an $\mathrm{H}_{3} \mathrm{O}^{+}$at the interface. Here the $\mathrm{H}$ in $-\mathrm{NH}_{3}$ starts at an initial distance of $3.79 \AA$ from the $\mathrm{H}$ in $\mathrm{H}_{3} \mathrm{O}^{+}$. Initially, the $\mathrm{H}$ in $\mathrm{H}_{3} \mathrm{O}^{+}$forms a hydrogen bond with the nearby $\mathrm{H}_{2} \mathrm{O}$ molecules in the solution. Along the reaction path the $\mathrm{HB}$ to the $\mathrm{H}_{2} \mathrm{O}$ breaks and the $\mathrm{H}$ moves down to the $\mathrm{H}$ of the $-\mathrm{NH}_{3}$ in $\mathrm{MA}^{+}$, while at the same time the orientation of $\mathrm{MA}^{+}$changes slightly so that the $-\mathrm{NH}_{3}$ orients upward. In the $\mathrm{TS}$, the distance is $1.42 \AA$ between these two $\mathrm{H}$ atoms that will form $\mathrm{H}_{2}$, leading to an energy barrier of $1.34 \mathrm{eV}$. In this case, there should be an $\mathrm{H}_{3} \mathrm{O}^{+}$on the top of a $\mathrm{MA}^{+}$molecule. However, the concentration of $\mathrm{H}_{3} \mathrm{O}^{+}$at the interface is small, reducing the probability for this reaction. The reaction processes and the TS structures for the above three cases can be found in Fig. S2 of Supporting Information.

The remaining possibility is that both $\mathrm{H}$ in $\mathrm{H}_{2}$ derive from surface $\mathrm{MA}^{+}$cations (case $\mathrm{d}$ in Fig. 1). This leads to an intermediate state with one $\mathrm{H}$ dissociating from $\mathrm{MA}^{+}$to form an intermediate state in which this $\mathrm{H}$ bonds to the $\mathrm{Pb}$ in the lead iodide layer. This extra $\mathrm{H}$ atom on the $\mathrm{Pb}$ atom breaks the symmetry of lead iodide layer lifting the $\mathrm{Pb}$ atom up by $0.4 \AA$. Prior to binding the $\mathrm{H}$, the $\mathrm{Pb}$ atom bonds to four I atoms in the lead iodide layer with bond distances from $3.19 \AA$ to $3.26 \AA$, but after the formation of $\mathrm{Pb}-\mathrm{H}$ bond, the $\mathrm{Pb}$ atom bonds only with two I atoms at the normal bond distances of $3.13 \AA$ and $3.19 \AA$, while the distances to the other two I atoms in the same layer lie at $3.72 \AA$ and $3.99 \AA$. Thus, we can consider that it makes a covalent bond to the $\mathrm{H}$ and two half electron ionic bonds to the two I neighbors. Formally the $\mathrm{H}$ in $\mathrm{Pb}-\mathrm{H}$ site can be thought of as $\mathrm{H}^{-}$with the valence of $\mathrm{Pb}$ of +2 , so that the excess electron is on the $\mathrm{H}-\mathrm{Pb}$ site. It is interesting that the intermediate structure has transformed to a semiconductor with the band gap of $2.04 \mathrm{eV}$, which is shown in Fig. S3 of Supporting Information.

The next step is for another $\mathrm{H}$ from an adjacent $\mathrm{MA}^{+}$molecule to react with the $\mathrm{H}$ of the $\mathrm{Pb}-\mathrm{H}$ to generate $\mathrm{H}_{2}$ (here for convenience we show both $\mathrm{H}$ as coming from the same $\mathrm{MA}^{+}$). This twostep reaction process for HER is shown in Fig. 2. In the first step, the $\mathrm{H}$ in the $-\mathrm{NH}_{3}$ starts at $3.09 \AA$ from the nearest $\mathrm{Pb}$ atom. Then, as the $\mathrm{H}$ migrates from the $\mathrm{MA}^{+}$to the $\mathrm{Pb}$, the $\mathrm{Pb}-\mathrm{H}$ distance decreases to $2.17 \AA$ at the TS. At this point, the $\mathrm{MA}^{+}$becomes a $\mathrm{CH}_{3} \mathrm{NH}_{2}$ molecule, with an $\mathrm{H}$ from a neighboring $\mathrm{H}_{2} \mathrm{O}$ making an $\mathrm{HB}$ with the lone pair on the $\mathrm{N}$ atom in $\mathrm{CH}_{3} \mathrm{NH}_{2}$. This facilitates rotation of the $\mathrm{CH}_{3} \mathrm{NH}_{2}$ to form the $\mathrm{HB}$, followed by transfer of the $\mathrm{H}$ from $\mathrm{H}_{2} \mathrm{O}$ into $\mathrm{CH}_{3} \mathrm{NH}_{2}$ molecule to form a new $\mathrm{MA}^{+}$, simultaneous with the $\mathrm{H}^{+}$from a neighbor $\mathrm{H}_{3} \mathrm{O}^{+}$in the solution migrating to form a new $\mathrm{H}_{2} \mathrm{O}$. Thus, there is a Grotthuss chain involving:

$$
\mathrm{CH}_{3} \mathrm{NH}_{2}+\mathrm{H}_{2} \mathrm{O}+\mathrm{H}_{3} \mathrm{O}^{+} \rightarrow \mathrm{CH}_{3} \mathrm{NH}_{3}{ }^{+}+\mathrm{H}_{2} \mathrm{O}+\mathrm{H}_{2} \mathrm{O}
$$

The free energy barrier for the proton transferring through water chains by a Grotthuss mechanism is as low as $0.12 \mathrm{eV},{ }^{19}$ which leads to very fast recovery of the surface $\mathrm{MA}^{+}$cations. Here, the energy barrier for forming the intermediate state is $1.08 \mathrm{eV}$ with consumption of one proton from the solution.

In the second step, we start from the intermediate state of lead hydride with a $\mathrm{Pb}-\mathrm{H}$ bond distance of $1.97 \AA$ with the $\mathrm{H}$ pointing toward a surface $\mathrm{MA}^{+}$molecule at an $\mathrm{H}-\mathrm{H}$ non-bond distance of $1.35 \AA$. Due to the $\mathrm{H}^{-}$at the $\mathrm{Pb}-\mathrm{H}$ site, the $\mathrm{H}^{+}$in the $\mathrm{MA}^{+}$cation moves to $\mathrm{PbH}^{-}$to generate $\mathrm{H}_{2}$. Thus, the reaction can be written as: $\mathrm{H}^{+}+\mathrm{PbH}^{-}=\mathrm{Pb}+\mathrm{H}_{2}$, where the $\mathrm{Pb}$ atom loses part of the extra electron to recover the $\mathrm{Pb}^{2+}$. As these two $\mathrm{H}$ atoms move to each other to form an $\mathrm{H}_{2}$ molecule, the $\mathrm{H}$ atom on a neighboring $\mathrm{H}_{2} \mathrm{O}$ transfers to the $\mathrm{CH}_{3} \mathrm{NH}_{2}$ molecule to form a new $\mathrm{MA}^{+}$cation, simultaneous with the proton from an $\mathrm{H}_{3} \mathrm{O}^{+}$transferring to recover this $\mathrm{H}_{2} \mathrm{O}$, another Grotthuss chain as in equation (5).

In this second step reaction, the calculated energy barrier is $0.08 \mathrm{eV}$ with consumption of a second $\mathrm{H}^{+}$, and an exothermicity of $2.30 \mathrm{eV}$. As shown in Fig. 2, the two $\mathrm{H}$ forming $\mathrm{H}_{2}$ are highlighted by green color for the first $\mathrm{H}$ and yellow color for the second $\mathrm{H}$. The diffusion of the proton during the reaction process is highlighted by cyan color. The rate determining step for the $\mathrm{H}_{2}$ generation is the first step with the energy barrier of $1.08 \mathrm{eV}$, while the photocatalytic HER reaction releases a total energy of $3.65 \mathrm{eV}$ by consuming two electrons and two protons. This energy barrier is comparable to that of $0.92 \mathrm{eV}$ for photocatalytic HER reaction on $\mathrm{TiO}_{2}$ surface. ${ }^{20}$

Summarizing our calculations, we find the following chemical mechanism for $\mathrm{H}_{2}$ evolution:

$$
\begin{gathered}
\text { (I) } \mathrm{CH}_{3} \mathrm{NH}_{3}^{+}+\mathrm{Pb}+2 \mathrm{e}^{-} \rightarrow \mathrm{CH}_{3} \mathrm{NH}_{2}+\mathrm{PbH}^{-}, \\
\mathrm{H}_{3} \mathrm{O}^{+}+\mathrm{CH}_{3} \mathrm{NH}_{2} \rightarrow \mathrm{CH}_{3} \mathrm{NH}_{3}^{+}+\mathrm{H}_{2} \mathrm{O} \\
\text { (II) } \mathrm{PbH}^{-}+\mathrm{CH}_{3} \mathrm{NH}_{3}^{+} \rightarrow \mathrm{Pb}+\mathrm{CH}_{3} \mathrm{NH}_{2}+\mathrm{H}_{2}, \\
\mathrm{H}_{3} \mathrm{O}^{+}+\mathrm{CH}_{3} \mathrm{NH}_{2} \rightarrow \mathrm{CH}_{3} \mathrm{NH}_{3}^{+}+\mathrm{H}_{2} \mathrm{O}
\end{gathered}
$$




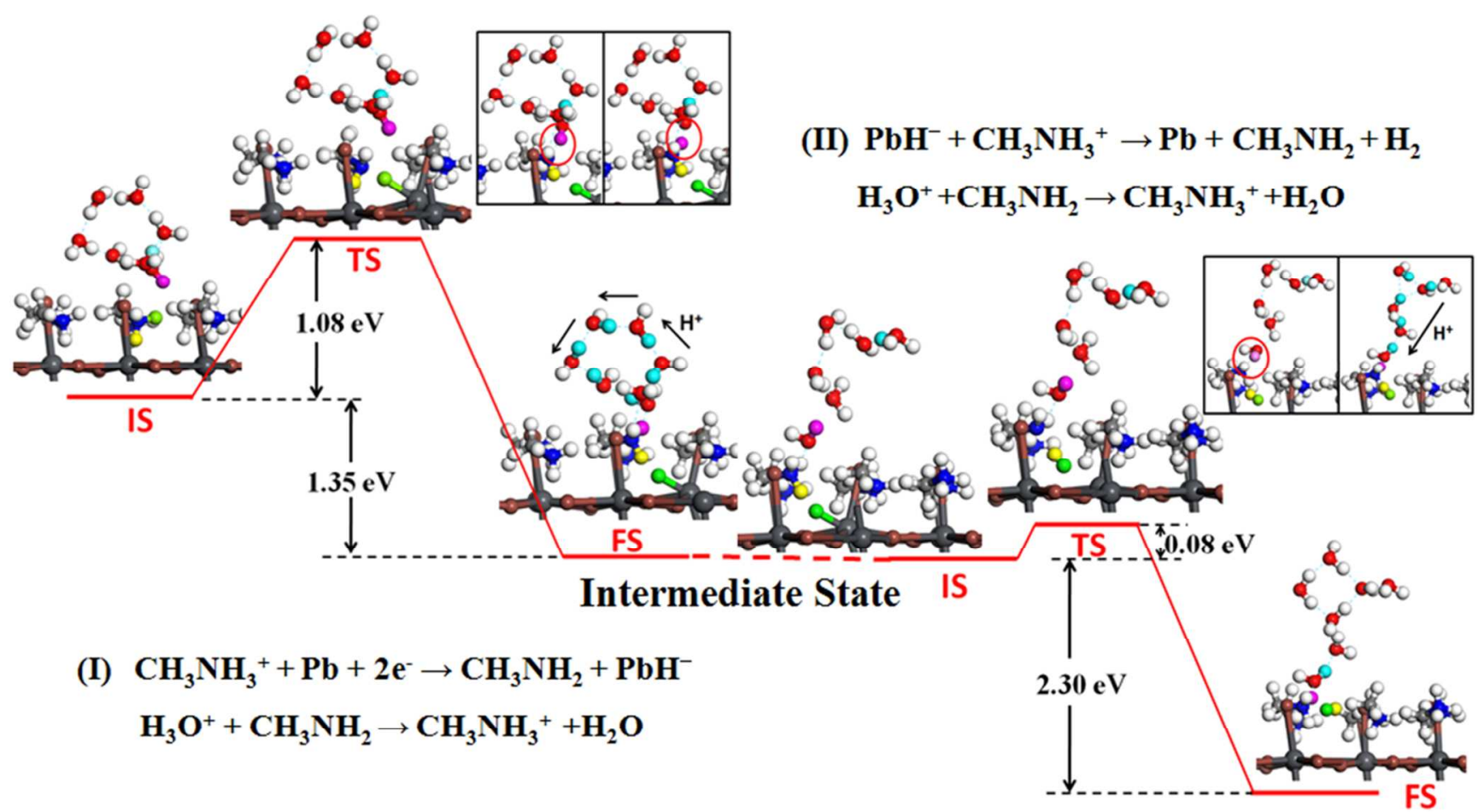

Fig. 2. Pb-activated amine-assisted (PbAAA) reaction pathway for $\mathrm{H}_{2}$ generation on $\mathrm{MAPbI}_{3}$ surface in acidic solvent. Most of the water molecules in our system are deleted in this figure in order to see more clearly with the water molecules involved in the diffusion of the protons left. The green and the yellow balls are two $\mathrm{H}$ from $\mathrm{MA}^{+}$, and the purple ball is the $\mathrm{H}$ in $\mathrm{H}_{2} \mathrm{O}$. The cyan color indicates the proton diffusing along the water chains.

This Pb-activated amine-assisted (PbAAA) mechanism involves three important factors that determine the rate of the HER reaction. First, the $\mathrm{Pb}$ atom in $\mathrm{MAPbI}_{3}$ plays an important role in promoting the $\mathrm{H}_{2}$ generation by stabilizing the $\mathrm{PbH}$ intermediate state. Second, the flexibility of the surface $\mathrm{MA}^{+}$molecule allows it to transfer the $\mathrm{H}$ to the $\mathrm{Pb}$ atom and be re-protonated by the solvent. The third factor is the Grotthuss transfer of $\mathrm{H}_{3} \mathrm{O}^{+}$in solution through one or more intermediate $\mathrm{H}_{2} \mathrm{O}$ to regenerate the surface $\mathrm{MA}^{+}$cations. We also calculated the same reaction mechanism for $\mathrm{H}_{2}$ generation in the dark. We find an energy barrier of $2.61 \mathrm{eV}$, which is discussed and shown in Fig. S4 of Supporting Information.

Summarizing, we carried out QM calculations in explicit solvent for the photocatalyzed HER reaction on the $\mathrm{MAPbI}_{3}$ surface. This leads to a novel PbAAA kinetic mechanism driven by both $\mathrm{Pb}$ atoms and the surface $\mathrm{MA}^{+}$cations. In the photoexcited state, the excited electrons and holes are separated to promote the $\mathrm{Pb}$ and I atoms in the surface lead iodide layer, respectively. We find that the protons of $\mathrm{MA}^{+}$cation play an essential role in forming $\mathrm{H}_{2}$ as does the $\mathrm{Pb}$. The reaction involves two steps with an intermediate state forming a $\mathrm{Pb}-\mathrm{H}$ hydride bond. During the reaction process, two protons in the solution re-protonate the $\mathrm{MA}^{+}$via a Grotthuss mechanism with rotation of surface $\mathrm{MA}^{+}$cations to facilitate $\mathrm{H}_{2}$ generation. We find that, the rate determining first step has an energy barrier of $1.08 \mathrm{eV}$, with a total energy release of $3.65 \mathrm{eV}$ by consumption of two protons and two electrons. Our results indicate that the chemical nature of the organic perovskites plays a critical role in the photocatalytic HER reaction, serving as a photocatalyst. This suggests designing the perovskites toward their catalysts functionality in addition to their photoexcitation property.

\section{ASSOCIATED CONTENT}

\section{Supporting Information}

Details of computational method and structural models, discussions on electronic structures for initial and intermediate configurations, the HER reaction paths for case a to $\mathrm{c}$, and the PbAAA mechanism in the dark condition (PDF). The Supporting Information is available free of charge on the ACS Publications website.

\section{AUTHOR INFORMATION}

\section{Corresponding Author}

*lwang22@suda.edu.cn

*yyli@suda.edu.cn

*wag@wag.caltech.edu

Notes

The authors declare no competing financial interests.

\section{ACKNOWLEDGMENT}

This work was supported by the National Key Research and Development Program of China (Grants 2017YFA0204800 and 2017YFB0701600), the National Natural Science Foundation of China (Grants 21403146, 51761145013, 21673149). This research was also supported by the Joint Center for Artificial Photosynthe- 
sis, a DOE Energy Innovation Hub, supported through the Office of Science of the U.S. Department of Energy under Award No.DE-SC0004993. This project is also supported by the Fund for Collaborative Innovation Center of Suzhou Nano Science \& Technology, the Priority Academic Program Development of Jiangsu Higher Education Institutions.

\section{REFERENCES}

(1) Xing, G.; Mathews, N.; Sun, S.; Lim, S. S.; Lam, Y. M.; Grätzel, M.; Mhaisalkar, S.; Sum, T. C. Science 2013, 342, 344.

(2) Burschka, J.; Pellet, N.; Moon, S.-J.; Humphry-Baker, R.; Gao, P.; Nazeeruddin, M. K.; Gratzel, M. Nature 2013, 499, 316.

(3) Cho, H.; Jeong, S.-H.; Park, M.-H.; Kim, Y.-H.; Wolf, C.; Lee, C.-L.; Heo, J. H.; Sadhanala, A.; Myoung, N.; Yoo, S.; Im, S. H.; Friend, R. H.; Lee, T.-W. Science 2015, 350, 1222.

(4) Stranks, S. D.; Snaith, H. J. Nat. Nano. 2015, 10, 391.

(5) Tan, Z.-K.; Moghaddam, R. S.; Lai, M. L.; Docampo, P.; Higler, R.; Deschler, F.; Price, M.; Sadhanala, A.; Pazos, L. M.; Credgington, D.; Hanusch, F.; Bein, T.; Snaith, H. J.; Friend, R. H. Nat. Nano. 2014, 9, 687. (6) Xing, G.; Mathews, N.; Lim, S. S.; Yantara, N.; Liu, X.; Sabba, D.; Grätzel, M.; Mhaisalkar, S.; Sum, T. C. Nat. Mater. 2014, 13, 476.

(7) Zhu, H.; Fu, Y.; Meng, F.; Wu, X.; Gong, Z.; Ding, Q.; Gustafsson, M. V.; Trinh, M. T.; Jin, S.; Zhu, X. Y. Nat. Mater. 2015, 14, 636.

(8) Ahmadi, M.; Wu, T.; Hu, B. Adv. Mater. 2017, 29, 1605242.

(9) D'Innocenzo, V.; Grancini, G.; Alcocer, M. J. P.; Kandada, A. R. S.; Stranks, S. D.; Lee, M. M.; Lanzani, G.; Snaith, H. J.; Petrozza, A. Nat. Commun. 2014, 5, 3586.

(10) Miyata, A.; Mitioglu, A.; Plochocka, P.; Portugall, O.; Wang, J. T.W.; Stranks, S. D.; Snaith, H. J.; Nicholas, R. J. Nat. Phys. 2015, 11, 582.

(11) Stranks, S. D.; Eperon, G. E.; Grancini, G.; Menelaou, C.; Alcocer, M. J. P.; Leijtens, T.; Herz, L. M.; Petrozza, A.; Snaith, H. J. Science 2013, 342,341 .

(12) Park, S.; Chang, W. J.; Lee, C. W.; Park, S.; Ahn, H.-Y.; Nam, K. T. Nat. Energy 2016, 2, 16185.

(13) Hou, J.; Cao, S.; Wu, Y.; Gao, Z.; Liang, F.; Sun, Y.; Lin, Z.; Sun, L. Chem.-Eur. J. 2017, 23, 9481.

(14) Xu, Y.-F.; Yang, M.-Z.; Chen, B.-X.; Wang, X.-D.; Chen, H.-Y.; Kuang, D.-B.; Su, C.-Y. J. Am. Chem. Soc. 2017, 139, 5660.

(15) Fujishima, A.; Honda, K. Nature 1972, 238, 37.

(16) Schrauzer, G. N.; Guth, T. D. J. Am. Chem. Soc. 1977, 99, 7189.

(17) Chen, X.; Shen, S.; Guo, L.; Mao, S. S. Chem. Rev. 2010, 110, 6503.

(18) Hisatomi, T.; Kubota, J.; Domen, K. Chem. Soc. Rev. 2014, 43, 7520.

(19) Cheng, T.; Goddard, W. A.; An, Q.; Xiao, H.; Merinov, B.; Morozov, S. Phys. Chem. Chem. Phys. 2017, 19, 2666.

(20) Lucking, M.; Sun, Y.-Y.; West, D.; Zhang, S. Phys. Chem. Chem. Phys. 2015, 17, 16779. 


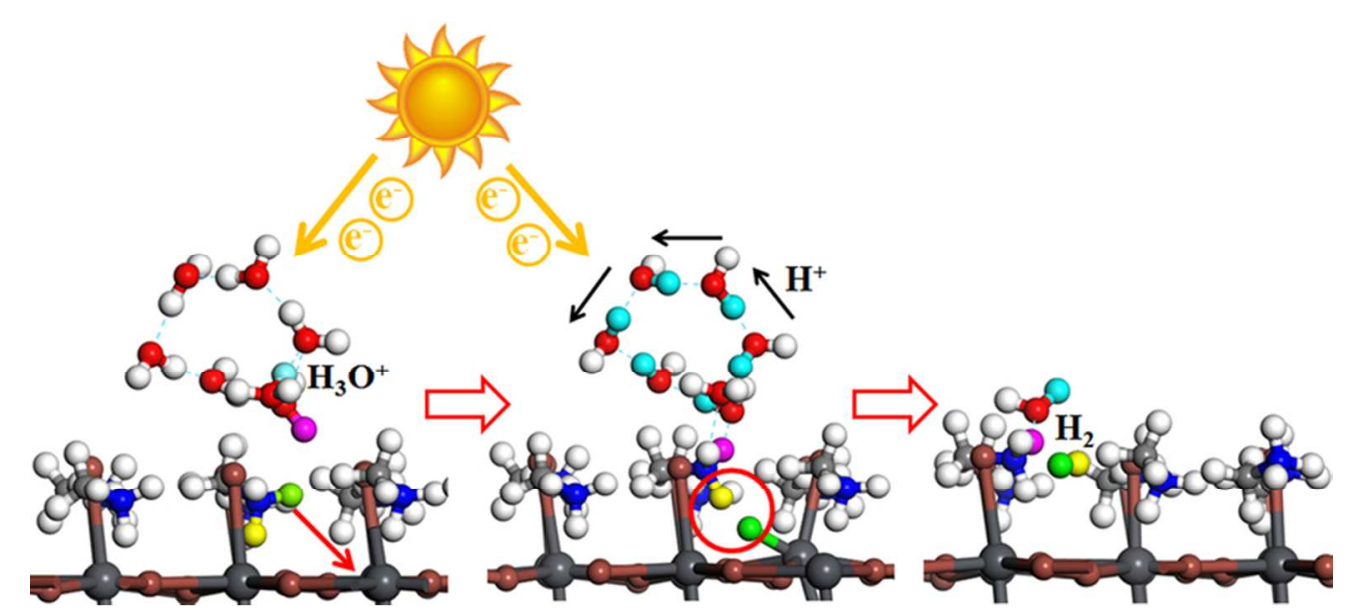

Organic-Inorganic perovskite converts visible light plus protons to $\mathrm{PbH}$ hydride and then to $\mathrm{H}_{2}$.

$37 \times 16 \mathrm{~mm}(600 \times 600 \mathrm{DPI})$ 